\title{
Biomechanical Assessment of Stabilization of Simulated Type II Odontoid Fracture with Case Study
}

\author{
Roy T. Daniel ${ }^{1}$, Mir M. Hussain ${ }^{2}$, Noelle Klocke ${ }^{2}$, Soumya S. Yandamuri ${ }^{2}$, \\ Lukas Bobinski ${ }^{1}$, John M. Duff ${ }^{1}$, Brandon S. Bucklen ${ }^{2}$ \\ ${ }^{1}$ Centre Hospitalier Universitaire Vaudois, Lausanne, Switzerland \\ ${ }^{2}$ Musculoskeletal Education and Research Center (MERC), A Division of Globus Medical, Inc., Audubon, PA, USA
}

Study Design: Researchers created a proper type II dens fracture (DF) and quantified a novel current posterior fixation technique with spacers at C1-C2. A clinical case study supplements this biomechanical analysis.

Purpose: Researchers explored their hypothesis that spacers combined with posterior instrumentation (PI) reduce range of motion significantly, possibly leading to better fusion outcomes.

Overview of Literature: Literature shows that the atlantoaxial joint is unique in allowing segmental rotary motion, enabling head turning. With no intervertebral discs at these joints, multiple ligaments bind the axis to the skull base and to the atlas; an intact odontoid (dens) enhances stability. The most common traumatic injury at these strong ligaments is a type II odontoid fracture.

Methods: Each of seven specimens (CO-C3) was tested on a custom-built six-degrees-of-freedom spine simulator with constructs of intact state, type II DF, C1-C2 PI, PI with joint capsulotomy (PIJC), PI with spacers (PIS) at C1-C2, and spacers alone (SA). A bending moment of $2.0 \mathrm{Nm}\left(1.5^{\circ} / \mathrm{sec}\right)$ was applied in flexion-extension (FE), lateral bending (LB), and axial rotation (AR). One-way analysis of variance with repeated measures was performed.

Results: DF increased motion to $320 \%, 429 \%$, and $120 \%$ versus intact (FE, LB, and AR, respectively). PI significantly reduced motion to $41 \%, 21 \%$, and $8 \%$. PIJC showed negligible changes from PI. PIS reduced motion to $16 \%, 14 \%$, and $3 \%$. SA decreased motion to $64 \%, 24 \%$, and $54 \%$. Reduced motion facilitated solid fusion in an 89-year-old female patient within 1 year.

Conclusions: Type II odontoid fractures can lead to acute or chronic instability. Current fixation techniques use C1-C2 Pl or an anterior dens screw. Addition of spacers alongside PI led to increased biomechanical rigidity over intact motion and may offer an alternative to established surgical fixation techniques.

Keywords: Type II dens fracture; Odontoid fracture; Atlantoaxial stabilization; Cervical biomechanics; Interarticular spacer

\section{Introduction}

The atlantoaxial joint lies bilaterally between the atlas (C1) and the axis (C2). It is unique in its capacity to allow segmental rotary motion, which enables head turning, as a result of its bone morphology and gliding articulating surfaces $[1,2]$. This unique morphologic configuration allows greater axial rotation (AR) than occurs anywhere

\footnotetext{
Received May 2, 2016; Revised Jun 20, 2016; Accepted Jul 16, 2016

Corresponding author: Mir M. Hussain

Musculoskeletal Education and Research Center (MERC), A Division of Globus Medical, Inc.,

2560 General Armistead Avenue, Audubon, PA 19403, USA

Tel: +1-610-930-1800 (ext. 2727), Fax: +1-610-930-2042, E-mail: mhussain@globusmedical.com
} 
else within the cervical spine [2-4]. In the absence of intervertebral discs at this joint, multiple ligaments bind the axis to the skull base and the atlas to provide stability to the atlantoaxial joint $[1,4]$. These stabilizing soft tissues of the craniocervical joint include, namely, the cruciate ligament with its transverse and vertical bands, apical and alar ligaments, the tectorial membrane, and anterior and posterior atlanto-occipital membranes. Atlantoaxial stability also depends on an intact odontoid process and an intact transverse ligament, which passes from one lateral mass of the axis, moves behind the odontoid process (a.k.a. dens), and attaches to the other lateral mass. The most common traumatic injury to the craniocervical junction is a type II odontoid fracture (dens fracture, DF), in which failure of bony structures tends to occur before ligamentous failure because of the strength of the ligaments [5,6]. Transverse and alar ligaments have ultimate tensile strength of $350 \mathrm{~N}$ and $200 \mathrm{~N}$, respectively [4]. Injury can lead to severe instability at $\mathrm{C} 1-\mathrm{C} 2$, requiring surgical intervention.

Standard methods used to stabilize a type II odontoid fracture injury consist of fusion techniques. Fusion in this region is important for re-stabilizing the area but can be problematic in elderly patients, who are more prone to DF. Anterior approaches generally result in high morbidity owing to difficulty in surgical access caused by placement of the atlantoaxial joint behind the mandible. Therefore, posterior approaches are used more commonly in this region [7-9]. Typical devices include transarticular screws, odontoid screws, and posterior cervical screws such as lateral mass screws or pedicle screws with rods [10-13]. Although biomechanical analysis of these methods shows adequate stability via decreased range of motion (ROM), odontoid screws have been associated clinically with a high rate of complications $[8,9]$ resulting from infection. The rate of nonunion is an area of focus because stability is a primary concern and complications such as infection may increase the nonunion rate [8,9]. Interarticular spacers (CORRIDOR, Globus Medical Inc., Audubon, PA, USA) have been used between articulating surfaces of $\mathrm{C} 1$ and $\mathrm{C} 2$ in conjunction with posterior fixation to help stabilize the joint for treatment of basilar invagination [14]. A similar surgical technique may offer a novel solution for fixating a DF. Although both lateral mass screws and $\mathrm{C} 1-\mathrm{C} 2$ spacers are used during a posterior approach, comparison of these fixation methods may yield essential information with regard to stability that may lead to pro- motion of fusion and reduction in revision rates. In this study, researchers assessed the biomechanical instability created when a novel type II DF model was created, and quantified the contribution of $\mathrm{C} 1-\mathrm{C} 2$ spacers when combined with posterior instrumentation (PI). The authors hypothesized that spacers combined with PI would reduce ROM significantly, possibly leading to better fusion outcomes.

To show how results of this study can be applied in a clinical situation, we present the case of an 89-year-old female patient, which incorporates a type II DF that required surgical intervention. We describe the outcome at 1-year follow-up when this novel C1-C2 spacer was used with posterior screw and rod fixation. This case study reflects the focus of the biomechanical study by illustrating use of this novel technique in an elderly patient with type II DF.

\section{Materials and Methods}

\section{Specimen preparation}

Seven fresh-frozen cadaver spines from occiput (C0) to C3 were used in this study. The medical history of each donor was reviewed, along with radiographs, so that specimens with spinal trauma, malignancy, deformity, or fracture that would otherwise affect the outcome of the test could be excluded. Specimens were carefully dissected, leaving only ligaments, bones, and intervertebral discs of desired segments. Specimens were fixed at the occiput with a custom-made fixation device, which provided easy intraoperative access to the superior aspect of the dens, and were potted distally at C3 with a 2:1 mixture of Bondo Auto Filler (Bondo/MarHyde Corp., Atlanta, GA, USA) and fiberglass resin (Home-Solutions All Purpose, Bondo/ MarHyde Corp.). All specimens were double-wrapped in plastics bags and were stored at $-20^{\circ}$ Celsius until the day of testing.

\section{Test setup and data analysis}

Each specimen was thawed overnight and was mounted on a six-degrees-of-freedom spine motion simulator. The occiput was mounted centrally to a gimble, which allowed translation in anterior-posterior and medial-lateral planes. The distal end (C3) was mounted to the base of the simulator, which allowed cranial-caudal translation 
during motion. A load-control protocol was used for testing, by which the specimen continued its course of motion until the desired load was met. For flexion-extension (FE), lateral bending (LB), and AR loading modes, an unconstrained pure moment was set at $\pm 2.0 \mathrm{Nm}$ at a rate of $1.5^{\circ} / \mathrm{sec}$ through motors attached to the gimble. Each loading mode consisted of three load/unload cycles, and data from the third cycle were analyzed. Markers were placed at C1 and C2. With these markers, investigators assessed ROM for intact and all surgical constructs by using the Optotrak Certus motion capture system (NDI Inc., Waterloo, ON, Canada).

In this study, a displaced type II DF was simulated without transverse ligamentous injury by resection of the odontoid along the long axis of the odontoid process from above (Fig. 1). Because of difficulty involved in accessing the dens, creation of the injury required removal of additional bones and ligaments, which is not normally done in a clinical setting. Previous biomechanical studies used approaches that disrupted the anterior longitudinal ligament (ALL), the tectorial membrane, or the posterior longitudinal ligament (PLL), or investigators removed $\mathrm{C} 1$ and C2 just to isolate the area [15-17]. The procedure reported here began with removal of the inferior clivus
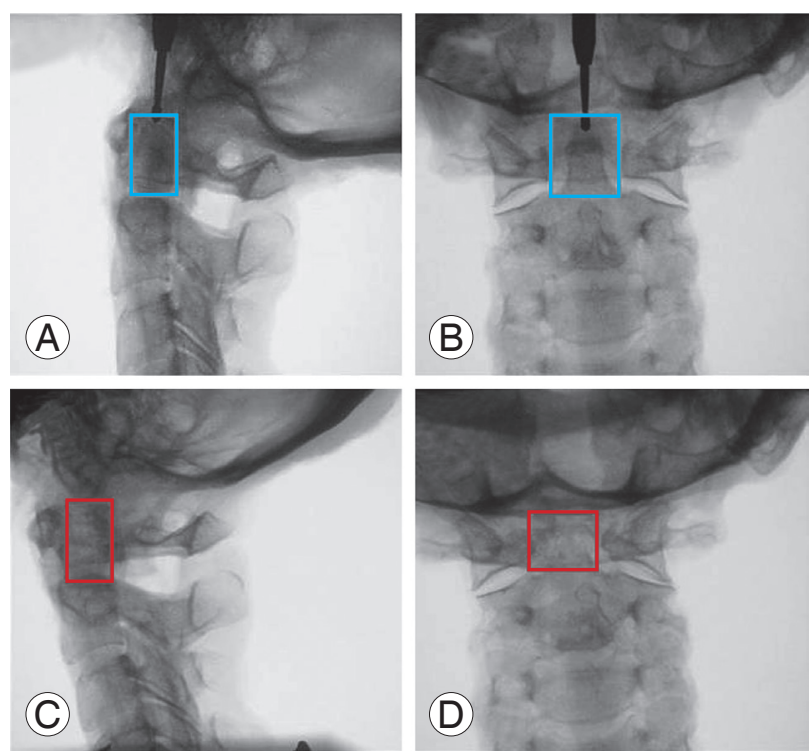

Fig. 1. (A) Lateral view of intact dens (blue box is around the dens) as drilling begins. (B) Anteroposterior (AP) view of intact dens (blue box is around the dens) as drilling begins. (C) Lateral view of fractured dens (red box). (D) AP view of fractured dens (red box). Statistical analysis was performed using analysis of variance with repeated measures to correlate significant $(p<0.05)$ differences between experimental constructs. with osteotomes to expose the tip of the odontoid process. Apical and alar ligaments were disrupted during this process. Then the odontoid process was hollowed from the superior process inferiorly along its internal axis to its base by a drill used along its length. Researchers used microcurettes to remove the outer shell of bone at the base of $\mathrm{C} 2$ to create the fracture, while taking care to preserve the transverse ligament. Fluoroscopy was used to verify complete resection of the odontoid (Fig. 1). Although the technique used to create injury in this study might have disrupted alar and apical ligaments, once the odontoid was fractured, the alar ligaments were no longer effective in limiting head rotation, as the odontoid was separated from the C2 vertebral body. All other ligaments were left intact. Clinically, this approach may be more destructive at the skull base, but in a laboratory setting, it best simulated the type II odontoid fracture without compromise of $\mathrm{C} 1$ and without impairment of the ALL. Other approaches to trauma involve removal of the $\mathrm{C} 2$ vertebral body and cannot be used to evaluate ROM [5].

\section{Surgical reconstruction}

Initially, specimens were tested for flexibility while joints were intact, so a baseline value could be determined. Subsequent to intact testing, researchers used surgical replications in the sequence presented in Fig. 2.

\section{Statistical methods}

Statistical analysis was performed using analysis of variance (ANOVA) with repeated measures to correlate significant $(\alpha<0.05)$ differences in ROM between experimental constructs. Tukey's honestly significant differences (HSD) test was used to determine statistical changes, hence $p$-values were not obtained. Tukey's HSD test for post-ANOVA comparisons requires a studentized range distribution statistic (Q) of the critical point (0.05), mean square error (MS), and degrees of freedom (df). The number of samples is also needed ( $\mathrm{n})$. Once those values are obtained, HSD can be computed by $\mathrm{HSD}_{.05}=\mathrm{Q}_{.05} *$ sqrt (MS/ N). Significance occurs when differences between constructs are equal to or greater than this value.

\section{Results}

Mean ROM for the intact condition at $\mathrm{C} 1-\mathrm{C} 2$ was 

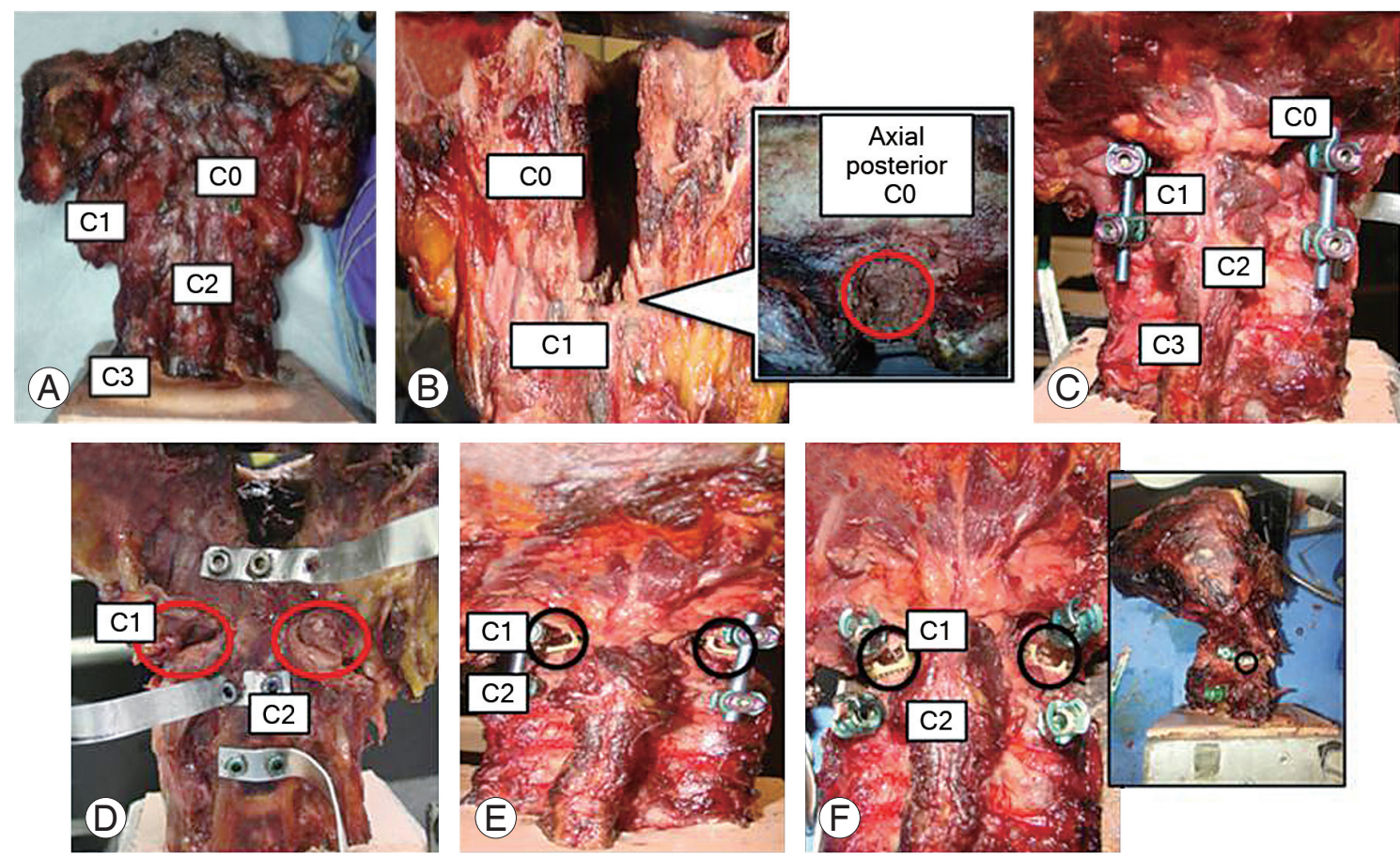

Fig. 2. Testing sequence for all specimens. (A) Anterior view of an intact specimen. (B) Dens fracture (DF) created by removal of the clivus (large image) with an axial view of the DF (small image). (C) Posterior view of posterior instrumentation (PI) construct. (D) Anterior view of joint capsulotomy during PI with joint capsulotomy. (E) Posterior view of PI with spacers. (F) Posterior (large image) and lateral views (small image) of spacers alone. Red circles represent instabilities created, and black circles indicate C1C2 washers.

Table 1. Normalized data (as percentage of intact condition) for all constructs

\begin{tabular}{|c|c|c|c|c|c|c|}
\hline Variable & Intact & DF & $\mathrm{PI}$ & PIJC & PIS & SA \\
\hline $\mathrm{FE}(\%)$ & $100 \pm 54.6$ & $319.6 \pm 130.8^{\mathrm{a})}$ & $41.0 \pm 37.1^{\mathrm{a}, \mathrm{b})}$ & $45.6 \pm 53.9^{a, b l}$ & $16.2 \pm 11.4^{a, b, c)}$ & $63.6 \pm 53.5^{b)}$ \\
\hline LB (\%) & $100 \pm 64.7$ & $429.3 \pm 354.5^{\text {al }}$ & $20.7 \pm 20.7^{\mathrm{a}, \mathrm{bl}}$ & $27.9 \pm 20.2^{\mathrm{a}, \mathrm{bl}}$ & $13.9 \pm 12.7^{\left.a^{a, b}\right)}$ & $24.5 \pm 31.7^{\mathrm{a}, \mathrm{b}}$ \\
\hline AR $(\%)$ & $100 \pm 21.9$ & $120.3 \pm 20.6$ & $7.8 \pm 4.3^{3, \mathrm{ab})}$ & $8.5 \pm 5.0^{0, b)}$ & $2.9 \pm 2.9^{a, b, c)}$ & $46.7 \pm 46.5^{a, b}$ \\
\hline
\end{tabular}

$\mathrm{DF}$, dens fracture; PI, posterior instrumentation; PIJC, posterior instrumentation with joint capsulotomy; PIS, posterior instrumentation with spacers; SA, spacers alone; FE, flexion-extension; LB, lateral bending; AR, axial rotation.

${ }^{\text {a) }}$ Significant for intact; ${ }^{\text {b) }}$ Significant for dens fracture; ${ }^{\text {c) }}$ Significant for spacers alone.

$4.6^{\circ} \pm 2.5^{\circ}, 2.2^{\circ} \pm 1.4^{\circ}$, and $57.3^{\circ} \pm 12.6^{\circ}$ in $\mathrm{FE}, \mathrm{LB}$, and $\mathrm{AR}$, respectively. Creating the DF significantly $(p<0.05)$ increased motion to $14.7^{\circ} \pm 6.0^{\circ}$ and $9.5^{\circ} \pm 7.9^{\circ}$ in $\mathrm{FE}$ and $\mathrm{LB}$, respectively. ROM was increased in $\mathrm{AR}$ to $69.9^{\circ} \pm 11.8^{\circ}$, but this finding was not statistically significant when compared with intact. This can be observed in the Table 1, where data have been normalized to intact (100\%).

All instrumented constructs reduced motion compared with that seen in the injured construct (Fig. 3, normalized to intact). The PI construct significantly reduced motion to $2.1^{\circ} \pm 2.5,0.6^{\circ} \pm 0.5^{\circ}$, and $4.5^{\circ} \pm 2.5^{\circ}$ of intact motion in $\mathrm{FE}, \mathrm{LB}$, and AR, respectively. When joint capsulotomy was performed and PI was re-installed, ROM changed slightly to $1.9^{\circ} \pm 1.8^{\circ}, 0.5^{\circ} \pm 0.3^{\circ}$, and $4.5^{\circ} \pm 2.5^{\circ}$ of intact in $\mathrm{FE}, \mathrm{LB}$, and AR, respectively. The PI with spacers (PIS) construct showed the most rigid motion, which was reduced to $0.8^{\circ} \pm 0.5^{\circ}, 0.3^{\circ} \pm 0.3^{\circ}$, and $1.6^{\circ} \pm 1.6^{\circ}$ in $\mathrm{FE}, \mathrm{LB}$, and $\mathrm{AR}$, respectively. Spacers alone (SA) proved the least stable construct of the fixation methods, with increases in FE to $2.9^{\circ} \pm 2.5^{\circ}$ and in $\mathrm{AR}$ to $25.0^{\circ} \pm 26.7^{\circ}$ of intact. This increase in motion was statistically significant when compared with PIS, and the decrease in motion was statistically significant only for the injured construct in FE, whereas all other instrumented constructs showed significantly less 


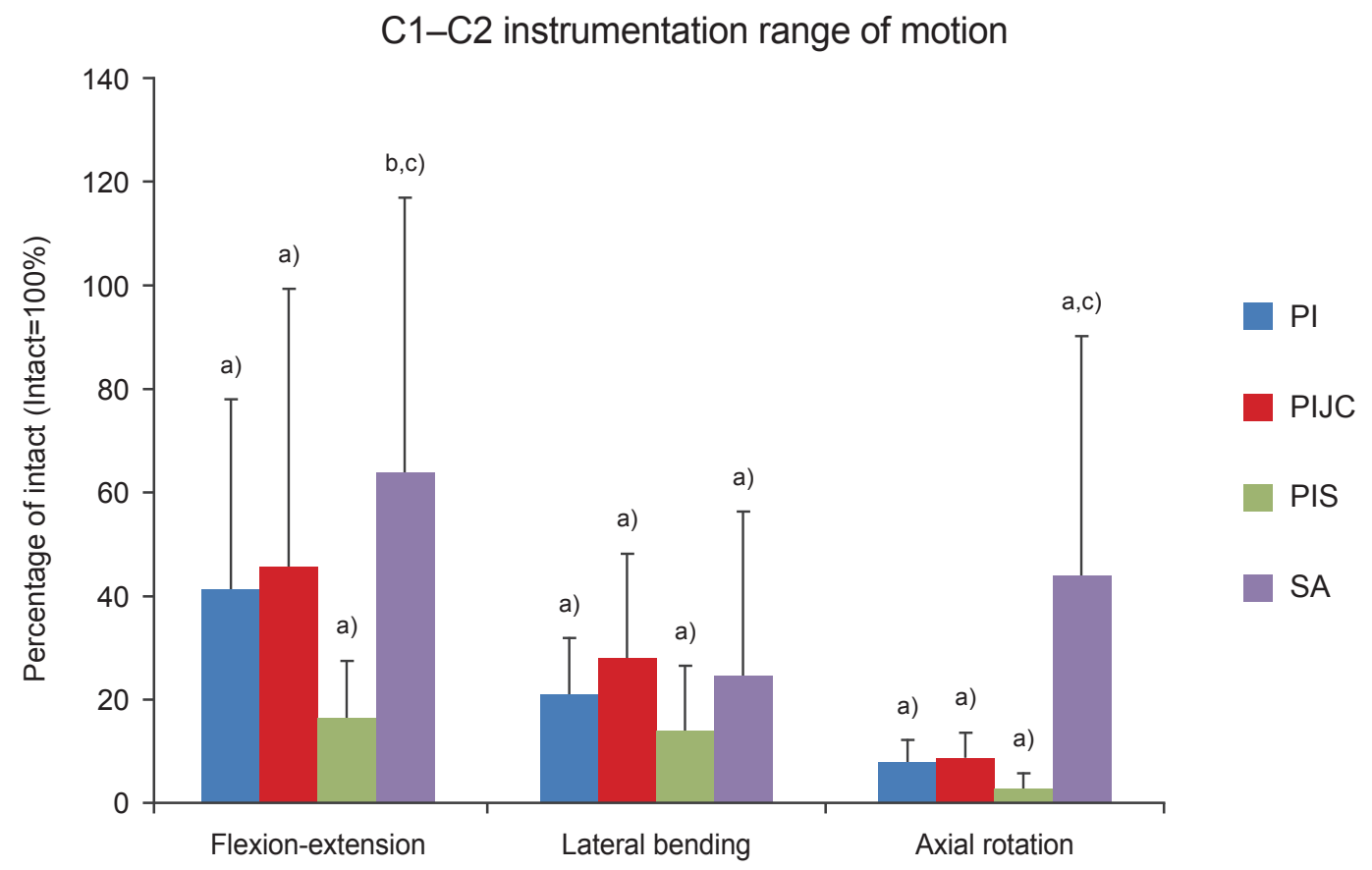

Fig. 3. Range of motion and statistical analysis of $\mathrm{C} 1-\mathrm{C} 2$ for each instrumented construct normalized to intact. Pl, posterior instrumentation; PIJC, PI with joint capsulotomy; PIS, PI with spacers; SA, spacers alone. ${ }^{\text {a) }}$ vs. Intact and injured; b) vs. injured only; ${ }^{c)}$ vs. PIS.
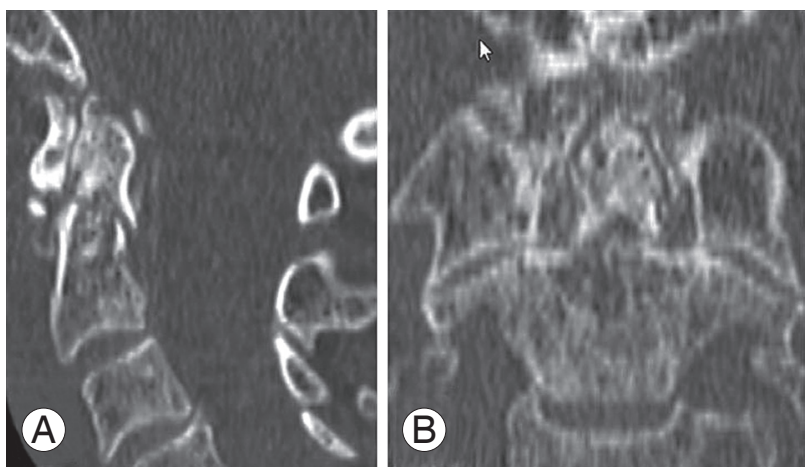

Fig. 4. Preoperative computed tomography scan shows the odontoid Anderson and D'Alonzo type II dens fracture. (A, B) Sagittal views.

motion for intact and injured. The SA construct, however, was similar to instrumented constructs in LB, with $0.6^{\circ} \pm 0.7^{\circ}$ of motion.

\section{Case study}

This case study provides clinical evidence of what can occur when posterior screws are used in conjunction with C1-C2 spacers. An 89-year-old female patient who had sustained a type II odontoid fracture was treated with a sternal occipital mandibular immobilizer brace without
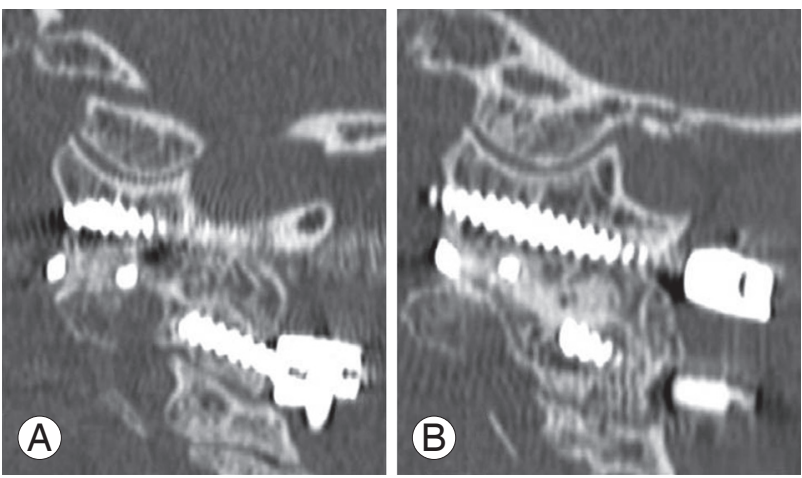

Fig. 5. Computed tomography scan 1 year after surgery. C1-C2 fusion can be observed across and posterior to the spacers. (A, B) Sagittal views.

signs of consolidation with secondary displacement (Fig. 4). The patient reported severe neck pain. Surgery was uneventful, as was postoperative hospitalization, and during follow-up, the patient demonstrated complete elimination of pain. Findings on neurologic examination were completely normal, except for limitations in neck movement, which did not disturb the patient. Radiologic investigation performed with spiral, thin-sliced computed tomography with multiplanar reconstruction revealed solid fusion across the spacers bilaterally, as well as solid bone behind the spacers (Figs. 5, 6). Functional cervical 


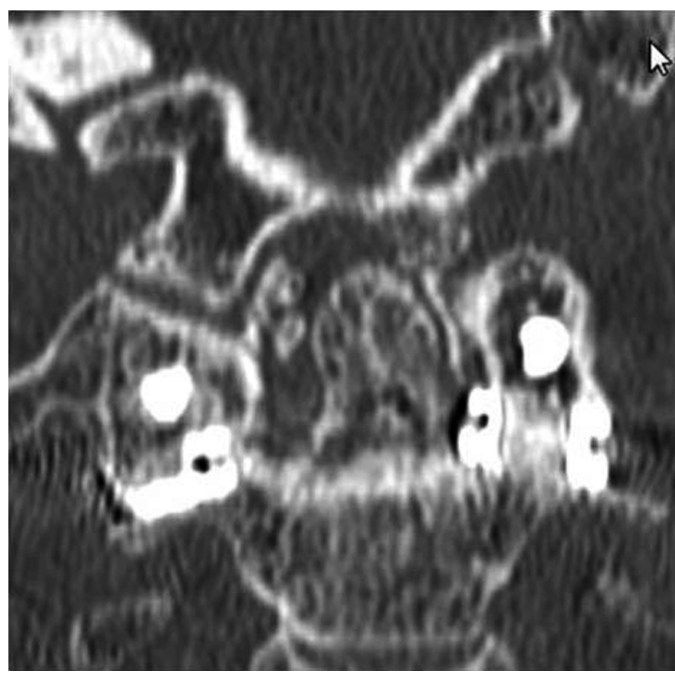

Fig. 6. Computed tomography scan 1 year after surgery. Coronal view shows solid bone fusion across the spacers in an almost pillar-like shape.
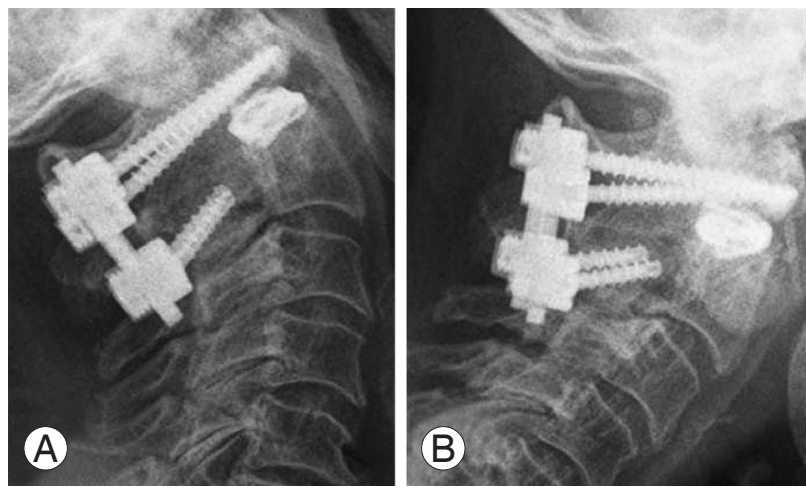

Fig. 7. Cervical functional X-rays show no detectable motion between $\mathrm{C} 1$ and $\mathrm{C} 2$ vertebrae. (A) Extension view. (B) Flexion view.

radiography with $\mathrm{FE}$ did not show movement between $\mathrm{C} 1$ and C2 (Fig. 7).

\section{Discussion}

DF injuries are difficult to create in vitro because access to the dens is limited. The injury model in the current study involved axial drilling of the dens with all ligaments left intact, with the exception of apical and alar ligaments. This model is similar to that used in a previous biomechanical study performed to test craniocervical dislocations $[18,19]$. It might accurately mimic a type II odontoid fracture because the base of the dens can be properly fractured without affecting the ALL, the PLL, or the C1 vertebral body. The clivus had to be removed by this technique, which caused disruption of the alar ligaments; however, once the dens was fractured, the contribution of alar ligaments to stability was considered moot. The injury as created in this model resulted in different outcomes than were reported by McCabe et al. [16], for whom a significant increase in AR preceded DF. In the current study, ROM was increased in AR, but this finding was not significant. The authors believe that this difference was due to use of different moments for testing. McCabe et al. [16] used $\pm 1 \mathrm{Nm}$, which may have resulted in decreased intact motion while increasing the injured state, as less force is required to move that construct. Also, the larger sample size would achieve better statistical power. FE and LB in this study showed significant increases-a finding that was also reported by McCabe et al. [16] and Ivancic et al. [20]. Results indicate that this unique injury creation model led to instability comparable with that described in previous work.

PI limits atlantoaxial joint movement to achieve bony union posteriorly between posterior elements, or laterally within atlantoaxial joints, or within the fracture itself. A type II DF is most commonly treated through posterior $\mathrm{C} 1-\mathrm{C} 2$ fixation or by insertion of a single lag screw through the $\mathrm{C} 2$ body into the dens from an anterior approach. Currently, appropriate treatment is determined on the basis of spinal injury characteristics and surgeon experience and preference $[11,16,21,22]$. Anterior surgery, however, can lead to complications such as dysphagia and dysphonia [23]. Although odontoid screws have been associated with excellent outcomes in terms of bony union and motion preservation, access is more difficult to achieve than with posterior fixation [10,24-26]. Indications for odontoid screw fixation are much more limited than for posterior fixation, and fusion outcomes change drastically with elderly patients $[8,9]$. Alignment of the fracture is crucial, as is patient anatomy, in the decision of whether anterior screw placement is the best option [11]. The degree of separation may make use of anterior screws difficult because of lagging complications [26]. Furthermore, preserving motion may not always be a crucial issue, especially when elderly individuals are treated. In a DF study, Lakshmanan et al. [27] concluded that $56 \%$ of patients suffered from osteoporosis. ROM can be severely limited by osteoarthritis at the $\mathrm{C} 1-\mathrm{C} 2$ joint.

Although biomechanical researchers have reported no statistically significant differences in ROM, they have found that some methods provide greater reduction in ROM than others $[11-13,20]$. Deviations within each 
spine and limited sample size have resulted in lack of significant differences between PI and constructs with spacers. The novel approach of using intervertebral spacers at $\mathrm{C} 1-\mathrm{C} 2$ takes advantage of intact ligaments by maintaining tension onto the spacers, thus stabilizing joints. Differences have been observed between PI alone and PIS in all loading modes; the latter approach is most effective in $\mathrm{FE}$ and AR. This research, although not clinical, also tested PI with joint capsulotomy, allowing quantitative analysis of how spacing created between $\mathrm{C} 1$ and $\mathrm{C} 2$ affects motion.

Daniel et al. [14] used the same spacer and screw construct to test biomechanical stability in a case of basilar invagination. In the Daniel et al's [14] study, SA led to great reduction in motion-a finding that is contradictory to outcomes reported in the present study. This difference in results could be due to lax transverse and alar ligaments (caused by the DF injury) that allow the joints to move freely. However, Daniel et al. [14] did not create an injury and thus left additional stabilizing elements in place. Robertson et al. [28] performed a similar study and used a novel approach with C1-C2 interface fixation. Investigators found statistical equivalence to all constructs, with the interface fixation device reducing motion to the greatest extent. Again, changes to injury methods may have led to outcomes different from those reported here. In the current study, spacers were sufficient for providing stability, but results were inconsistent in that some specimens demonstrated motion, leading to higher averages and higher standard deviations. SA produced significantly lower averages than were noted in the injured construct in $\mathrm{FE}$, indicating that use of SA is not sufficient.

Type II DF generally happens in the elderly as a result of weakened bone $[16,29]$. The average person is living longer, and the prevalence of this injury may increase. Complications of nonunion, particularly in anterior correction of type II DF, are frequently reported among the elderly [11]. In the case study presented, the patient was 89 years old, yet fusion was achieved in a columnar fashion through the use of spacers; this may have been difficult to accomplish through other techniques. The approach described here provides a rigid construct with greater potential for bone growth. The authors of the present study believe that scraping and preparing the articular joint promotes bone growth, as has been seen in discectomy and endplate preparation techniques used in interbody fusion, but that construct rigidity, in terms of motion, remains stable until fusion occurs. Concerns regarding vertebral artery complications can be addressed by care and repositioning, as was discussed in previous clinical cases reported by Bobinski et al. [30], in which spacers as large as 10 $\mathrm{mm}$ were used in the $\mathrm{C} 1-\mathrm{C} 2$ articular joint. Finally, this technique allows use of a posterior approach only, thereby reducing the number of surgical incisions.

In the present study, researchers performed a biomechanical test with inherent limitations. No loads were included to simulate the weight of the head, and motion was applied at $\mathrm{C} 0$ rather than at each individual vertebral body. The clivus was removed to gain access, but this would not occur during repair of a type II fracture in a clinical setting. All muscles were removed as well, making forces different from those encountered in an in vivo setting.

\section{Conclusions}

A type II DF can cause segmental instability predominantly in FE and AR. A biomechanical simulation of this injury model has been created, in which the transverse ligament, the ALL, and the PLL were kept intact. Although current anterior methods with fairly narrow indications are available, $\mathrm{PI}$ is used more frequently to treat $\mathrm{C} 1-\mathrm{C} 2$ instability. Even though this technique provides adequate fixation, a novel approach in which spacers are used to stabilize the $\mathrm{C} 1-\mathrm{C} 2$ joint provides additional rigidity over posterior screws used alone and may allow bone growth. Rigidity and joint preparation may allow bone growth even in the geriatric population, for whom fusion rates can be problematic. This theory is supported by the clinical case provided; however, this case represents only one example. A larger clinical study would better reveal potential clinical benefits.

\section{Conflict of Interest}

Authors M.M.H., N.K., S.S.Y., and B.S.B. are salaried employees of Globus Medical Inc. Authors RTD, LB, and JMD have no relationships to disclose. All biomechanical testing was performed at Globus Medical Inc.

\section{Acknowledgments}

Portions of this work were presented at the 14th Annual Conference of the International Society for the Advancement of Spine Surgery (ISASS), Biomechanics Session, held in Miami, Florida, from April 30 to May 2, 2014. 
The authors would like to acknowledge Dolores Matthews, MEd, ELS, for her contributions in editing this manuscript.

\section{References}

1. Tubbs RS, Hallock JD, Radcliff V, et al. Ligaments of the craniocervical junction. J Neurosurg Spine 2011; 14:697-709.

2. Bellabarba C, Mirza SK, Chapman JR. Injuries of the craniocervical junction. In: Bucholz RW, Heckman JD, Court-Brown CM, editors. Rockwood \& Green's fractures in adults. 6th ed. Philadelphia: Lippincott Williams \& Wilkins; 2006. p.1436-96.

3. Dickman CA, Mamourian A, Sonntag VK, Drayer BP. Magnetic resonance imaging of the transverse atlantal ligament for the evaluation of atlantoaxial instability. J Neurosurg 1991;75:221-7.

4. Dvorak J, Schneider E, Saldinger P, Rahn B. Biomechanics of the craniocervical region: the alar and transverse ligaments. J Orthop Res 1988;6:452-61.

5. Ames CP, Crawford NR, Chamberlain RH, Deshmukh V, Sadikovic B, Sonntag VK. Biomechanical evaluation of a bioresorbable odontoid screw. J Neurosurg Spine 2005;2:182-7.

6. Aryan HE, Newman CB, Nottmeier EW, Acosta FL Jr, Wang VY, Ames CP. Stabilization of the atlantoaxial complex via C-1 lateral mass and $\mathrm{C}-2$ pedicle screw fixation in a multicenter clinical experience in 102 patients: modification of the Harms and Goel techniques. J Neurosurg Spine 2008;8:222-9.

7. Cornefjord M, Henriques T, Alemany M, Olerud C. Posterior atlanto-axial fusion with the Olerud Cervical Fixation System for odontoid fractures and C1-C2 instability in rheumatoid arthritis. Eur Spine J 2003; 12:91-6.

8. Scheyerer MJ, Zimmermann SM, Simmen HP, Wanner GA, Werner CM. Treatment modality in type II odontoid fractures defines the outcome in elderly patients. BMC Surg 2013;13:54.

9. Tian NF, Hu XQ, Wu LJ, et al. Pooled analysis of nonunion, re-operation, infection, and approach related complications after anterior odontoid screw fixation. PLoS One 2014;9:e103065.

10. Dailey AT, Hart D, Finn MA, Schmidt MH, Apfelbaum RI. Anterior fixation of odontoid fractures in an elderly population. J Neurosurg Spine 2010;12:1-
8.

11. Denaro V, Papalia R, Di Martino A, Denaro L, Maffulli $\mathrm{N}$. The best surgical treatment for type II fractures of the dens is still controversial. Clin Orthop Relat Res 2011;469:742-50.

12. Lapsiwala SB, Anderson PA, Oza A, Resnick DK. Biomechanical comparison of four $\mathrm{C} 1$ to $\mathrm{C} 2$ rigid fixative techniques: anterior transarticular, posterior transarticular, $\mathrm{C} 1$ to $\mathrm{C} 2$ pedicle, and $\mathrm{C} 1$ to $\mathrm{C} 2$ intralaminar screws. Neurosurgery 2006;58:516-21.

13. Graziano G, Jaggers C, Lee M, Lynch W. A comparative study of fixation techniques for type II fractures of the odontoid process. Spine (Phila Pa 1976) 1993; 18:2383-7.

14. Daniel RT, Muzumdar A, Ingalhalikar A, Moldavsky M, Khalil S. Biomechanical stability of a posterioralone fixation technique after craniovertebral junction realignment. World Neurosurg 2012;77:357-61.

15. Oberkircher L, Bliemel C, Flossdorf F, Schwarting T, Ruchholtz S, Kruger A. Biomechanical evaluation of 2 insertion points for ventral screw fixation of C-2 dens fractures. J Neurosurg Spine 2013;18:553-7.

16. McCabe CM, McLachlin SD, Bailey SI, Gurr KR, Bailey CS, Dunning CE. The effect of soft-tissue restraints after type II odontoid fractures in the elderly: a biomechanical study. Spine (Phila Pa 1976) 2012;37: 1030-5.

17. Wilke HJ, Fischer K, Kugler A, Magerl F, Claes L, Worsdorfer $\mathrm{O}$. In vitro investigations of internal fixation systems of the upper cervical spine: I. Stability of the direct anterior screw fixation of the odontoid. Eur Spine J 1992;1:185-90.

18. Radcliff KE, Hussain MM, Moldavsky M, et al. Stabilization of the craniocervical junction after an internal dislocation injury: an in vitro study. Spine J 2015;15:1070-6.

19. Radcliff KE, Hussain MM, Moldavsky M, et al. In vitro biomechanics of the craniocervical junction: a sequential sectioning of its stabilizing structures. Spine J 2015;15:1618-28.

20. Ivancic PC, Beauchman NN, Mo F, Lawrence BD. Biomechanics of halo-vest and dens screw fixation for type II odontoid fracture. Spine (Phila Pa 1976) 2009;34:484-90.

21. Konieczny MR, Gstrein A, Muller EJ. Treatment algorithm for dens fractures: non-halo immobilization, anterior screw fixation, or posterior transarticu- 
lar C1-C2 fixation. J Bone Joint Surg Am 2012;94: e144(1-6).

22. Dmitriev AE, Lehman RA Jr, Helgeson MD, Sasso RC, Kuhns C, Riew DK. Acute and long-term stability of atlantoaxial fixation methods: a biomechanical comparison of pars, pedicle, and intralaminar fixation in an intact and odontoid fracture model. Spine (Phila Pa 1976) 2009;34:365-70.

23. Vasudevan K, Grossberg JA, Spader HS, Torabi R, Oyelese AA. Age increases the risk of immediate postoperative dysphagia and pneumonia after odontoid screw fixation. Clin Neurol Neurosurg 2014;126: 185-9.

24. Yang YL, Fu BS, Li RW, et al. Anterior single screw fixation of odontoid fracture with intraoperative IsoC 3-dimensional imaging. Eur Spine J 2011;20:1899907.

25. Hou Y, Yuan W, Wang X. Clinical evaluation of anterior screw fixation for elderly patients with type II odontoid fractures. J Spinal Disord Tech 2011;24: E75-81.
26. Magee W, Hettwer W, Badra M, Bay B, Hart R. Biomechanical comparison of a fully threaded, variable pitch screw and a partially threaded lag screw for internal fixation of Type II dens fractures. Spine (Phila Pa 1976) 2007;32:E475-9.

27. Lakshmanan P, Jones A, Howes J, Lyons K. CT evaluation of the pattern of odontoid fractures in the elderly: relationship to upper cervical spine osteoarthritis. Eur Spine J 2005;14:78-83.

28. Robertson PA, Tsitsopoulos PP, Voronov LI, Havey RM, Patwardhan AG. Biomechanical investigation of a novel integrated device for intra-articular stabilization of the C1-C2 (atlantoaxial) joint. Spine J 2012; 12:136-42.

29. Chapman J, Bransford R. Geriatric spine fractures: an emerging healthcare crisis. J Trauma 2007;62(6 Suppl):S61-2.

30. Bobinski L, Levivier M, Duff JM. Occipitoaxial spinal interarticular stabilization with vertebral artery preservation for atlantal lateral mass failure. J Neurosurg Spine 2015;22:134-8. 